\title{
Anti-Treponema pallidum IgM, IgA, and IgG subclass antibody responses after treatment in patients with syphilis at various stages: 1. Assessments by enzyme-linked immunosorbent
} assay

\author{
Sinobu Tanaka, Takakazu Suzuki
}

\begin{abstract}
Patients with syphilis at various stages were followed from the beginning by serial measurements of antibodies against Treponema pallidum that belonged to the classes IgM and IgA, and to the subclasses IgG1 to 4 by an enzyme-linked immunosorbent assay. A marked decrease in levels of antibodies was noted within three months after treatment. In the case of IgM this occurred in 19 of the 31 patients studied $(61 \%)$, in the case of $\mathrm{IgA}$ in 15 patients $(48 \%)$ and in the case of one or more of the subclasses of IgG in 18 patients (52\%). These findings indicate the usefulness of levels of IgM antibodies as markers for evaluating the effects of treatment. There were, nevertheless, 12 patients (39\%) whose levels of IgM antibodies remained consistently below the normal limits or failed to decline despite treatment. In five $(16 \%)$ of these cases, the serum level of IgA antibodies or of one or more subclasses of IgG fell after treatment. The results suggest the potential usefulness of $\operatorname{IgA}$ antibodies in the various IgG subclasses as a marker for evaluating the results of treatment in those patients whose levels of IgM antibodies do not change in response to treatment.
\end{abstract}

In patients with syphilis, the level of IgM antibodies against $T$ pallidum, which is known to decline in the circulation after treatment, is currently used as a marker for evaluating the effects of treatment. ${ }^{1-5}$

Tokyo Metropolitan Institute of Medical Science Department of Laboratory Animal Science Sinobu Tanaka

Department of Physiological Chemistry Tokyo Metropolitan Institute of Medical Science, Tokyo, Japan

Takakazu Suzuki
Levels of IgG antibodies do not change significantly with treatment in most instances, and they are generally thought to have little bearing upon assessment of the efficacy of treatment.

Patients with syphilis were followed from the beginning of treatment by measurements of levels of IgM and IgG, by the $T$ pallidum immune adherence (TPIA) test, conducted in our laboratory. ${ }^{6}$ The data showed a decrease in levels of IgG antibodies after treatment, even though the decrease was not as rapid as in the case of IgM antibodies. The decrease in levels of IgG antibodies, as demonstrated by the TPIA test which involves a reaction with complement, suggests a possible decrease in levels of antibodies that belong to a particular subclass(es) of IgG that is capable of binding complement. ${ }^{78}$ This possibility, in turn, suggests that such subclass(es) of IgG may prove to be useful markers for evaluating the efficacy of treatment. Responses by classes of Ig and/or subclass of IgG against $T$ pallidum have been reported from studies utilising the fluorescent antibody (FTA) test. ${ }^{910}$ enzyme-linked immunosorbent assay (ELISA ${ }^{11}$ ) and sodium dodecyl sulphate-polyacrylamide gel electrophoresis (SDSPAGE) immunoblotting. ${ }^{12}$ However, there is a dearth of information on changes in levels of antibodies of IgG subclasses after treatment of syphilitic patients; it is still unclear whether or not these immunoglobulins can serve as useful markers in the evaluation of the effects of treatment.

The present study was undertaken to investigate, using ELISA, the changes in levels of subclasses of anti- $T$ pallidum after treatment in patients with syphilis at various stages. The study also included assessments of levels of IgM antibodies in these patients, as well as of IgA antibodies, the behaviour of which has not been previously studied in patients undergoing treatment.

Materials and methods Sera: Sixty samples of normal human sera with no serological evidence of infection by $T$ pallidum as 
assessed by the TPHA, glass-plate and complement fixation tests were obtained from the Department of Laboratory Medicine, Tokyo Metropolitan Komagome Hospital. Sera from documented patients with syphilis were supplied by Drs $T$ Tsugami and M Matsunaga of the Prefectural Mandai Clinic, Osaka; by $\mathrm{Dr} T$ Kawashima of Metropolitan Ohkubo Hospital, Tokyo; and by Dr M Koga of the Department of Dermatology, Tokyo Medical College, Tokyo. The clinical diagnosis was primary syphilis in 20 of these patients, secondary syphilis in 12 patients, early latent syphilis in 12 patients and late latent syphilis in four patients.

Reagents: Immunologic reagents used in the study included sheep anti-human IgG1, 2, 3 and 4 (Binding Sites Ltd, Birmingham, UK), horseradish peroxidase (HRP)-labelled rabbit anti-sheep Ig (Cappel Laboratories, Cochranville, PA, USA), HRPlabelled sheep anti-human IgM (Cappel Laboratories), HRP-labelled rabbit anti-human IgA (Dako Immunoglobulins, Copenhagen, Denmark), HRP labelled rabbit anti-human IgG (ICN ImmunoBiologicals, Lisle, IL, USA), bovine gamma-globulin (BGG; Fraction V; ICN ImmunoBiologicals), bovine serum albumin (BSA; Seikagaku Industries Co Ltd, Tokyo), Tween 20 (Sigma Chemical Co, St Louis, MO, USA) and ophenylenediamine (Sigma Chemical Co).

$T$ pallidum antigen: $T$ pallidum was propagated in male New Zealand White rabbits inoculated into the testicle with $2 \times 10^{7}$ Nichols strain treponemes per animal. Testes were resected from the rabbits two weeks after inoculation, sliced and subjected to extraction of treponemes in sterile phosphate-buffered saline (PBS). The buffer after extraction was centrifuged at $330 \mathrm{~g}$ for 5 minutes, and the supernatant was recentrifuged at $10,000 \mathrm{~g}$ for 1 hour. The resultant sediment was layered in a glass tube that contained a stepwise glycerin density gradient $(5,10$, 15,20 and $40 \%$ ) and centrifuged at $1,300 \mathrm{~g}$ for 20 minutes. A layer of the fluid in the regions of $10 \%$ and $15 \%$ glycerin was transferred to a glass centrifuge tube, diluted with PBS and recentrifuged at $10,000 \mathrm{~g}$ for 1 hour. Sedimented treponemes were resuspended in PBS, adjusted to a concentration of $1 \times 10^{6}$ treponemes $/ \mathrm{ml}$, heated at $65^{\circ} \mathrm{C}$ for 1 hour, and sonicated at $10 \mathrm{kHz}$ for 5 minutes. Quantitation of protein in the preparation of antigen was carried out with the Bio-Rad protein assay (Bio-Rad Laboratories, Richmond, CA, USA) and BSA was used as a standard.

ELISA procedure: ELISA was performed in the wells of micro-ELISA plates (Immulon 600, Dynatech Laboratories Inc, Alexandria, VA, USA). An aliquot of $T$ pallidum antigen $(6.4 \mu \mathrm{g}$ protein $/ \mathrm{ml}$ of $0.1 \mathrm{M}$ bicarbonate buffer, ph 9.5) was placed in each well and the plates were incubated at $4^{\circ} \mathrm{C}$ for 48 hours. The plates were then washed five times with
PBS that contained $0.05 \%$ Tween 20 (PBS-Tween), and blocked with $5 \%$ BSA in $0.1 \mathrm{M}$ bicarbonate buffer, $\mathrm{pH} 9.5$, by incubations at $37^{\circ} \mathrm{C}$ for 1 hour. Test sera, diluted to optimal concentrations with PBS-Tween that contained 1\% BGG were added to the wells and the plates were incubated at $37^{\circ} \mathrm{C}$ for 1 hour. After the plates had been washed with PBSTween, aliquots of each subclass of anti-human IgG (IgG1, 2, 3, and 4), diluted with PBS-Tween that contained $1 \%$ BGG, were added to the wells and the plates were reincubated at $37^{\circ} \mathrm{C}$ for 1 hour and subsequently at $4^{\circ} \mathrm{C}$ for 16 hours. The plates were washed and allowed to stand at $37^{\circ} \mathrm{C}$ for 1 hour with added HRP-labelled anti-sheep Ig antibody. After washing, the substrate mixture, which consisted of a solution of $0.4 \mathrm{mg} / \mathrm{ml}$ of o-phenylenediamine and $0.01 \% \mathrm{H}_{2} \mathrm{O}_{2}$ in $0.05 \mathrm{M}$ sodium citrate-sodium phosphate buffer, $\mathrm{pH} 5 \cdot 5$, was added to the wells and the plates were incubated at room temperature for 20 minutes in the dark. Then an aliquot of $2 \mathrm{~N} \mathrm{HCl}$ was added to each well and the plates were read at $490 \mathrm{~nm}$ in a Dynatech Microelisa Autoreader MR 580. All reaction mixtures mentioned above were applied in volumes of $50 \mu \mathrm{l}$. The above assay procedure was modified for quantitation of antibodies belonging to IgM, IgA and IgG classes, in which case HRPlabelled antibodies against the respective classes were used. Assays were set up in triplicate and carried out twice for each specimen. Assay was performed on 60 syphilis-negative sera, and the upper normal limit was defined as the mean value of the 60 negative sera (x) plus twice the standard deviation (SD) of the mean. Negative sera showing titers at or in the close region of the upper normal limit were pooled and used as a standard. Assay results are expressed in terms of an ELISA index and the ELISA index was calculated by the formula:

ELISA index $=$ (mean value of sample) $/(\overline{\mathrm{x}}+2 \mathrm{SD})$

An ELISA index of 1 denotes, therefore, the upper normal limit.

\section{Results}

1. Distribution of antibodies at the Ig classes and $\operatorname{IgG}$ subclasses in sera that was serologically positive for syphilis.

Levels of antibodies of the Ig classes and IgG subclasses were determined in 60 normal sera and in 301 samples of sera from patients who were serologically positive for syphilis. Of the patient sera tested, $89 \%$ had levels of IgG antibodies in excess of the normal limit, $39 \%$ had elevated levels of IgM antibodies and $33 \%$ had elevated levels of IgA antibodies (fig 1). The low rate of positive results for the latter two classes may be attributable to the fact that a considerable fraction of the samples of patient sera had been obtained after the effective treatment of the patient. 


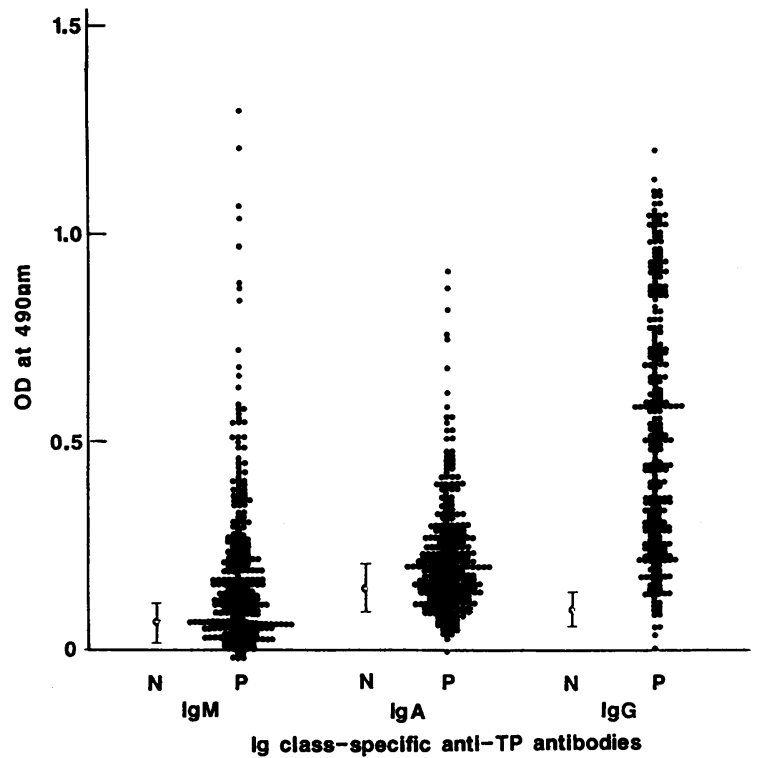

Figure 1 Levels of anti-T pallidum Ig classes in syphilis patients. $N$ denotes normal sera, and $P$ denotes serologically documented syphilitic patients.

Figure 2 shows levels of antibodies in the IgG subclasses; as determined in the samples of serum. Values above the normal limit were demonstrated for IgG1 in $77 \%$ of sera, for IgG2 in $64 \%$, for IgG3 in $56 \%$ and for IgG4 in $64 \%$.

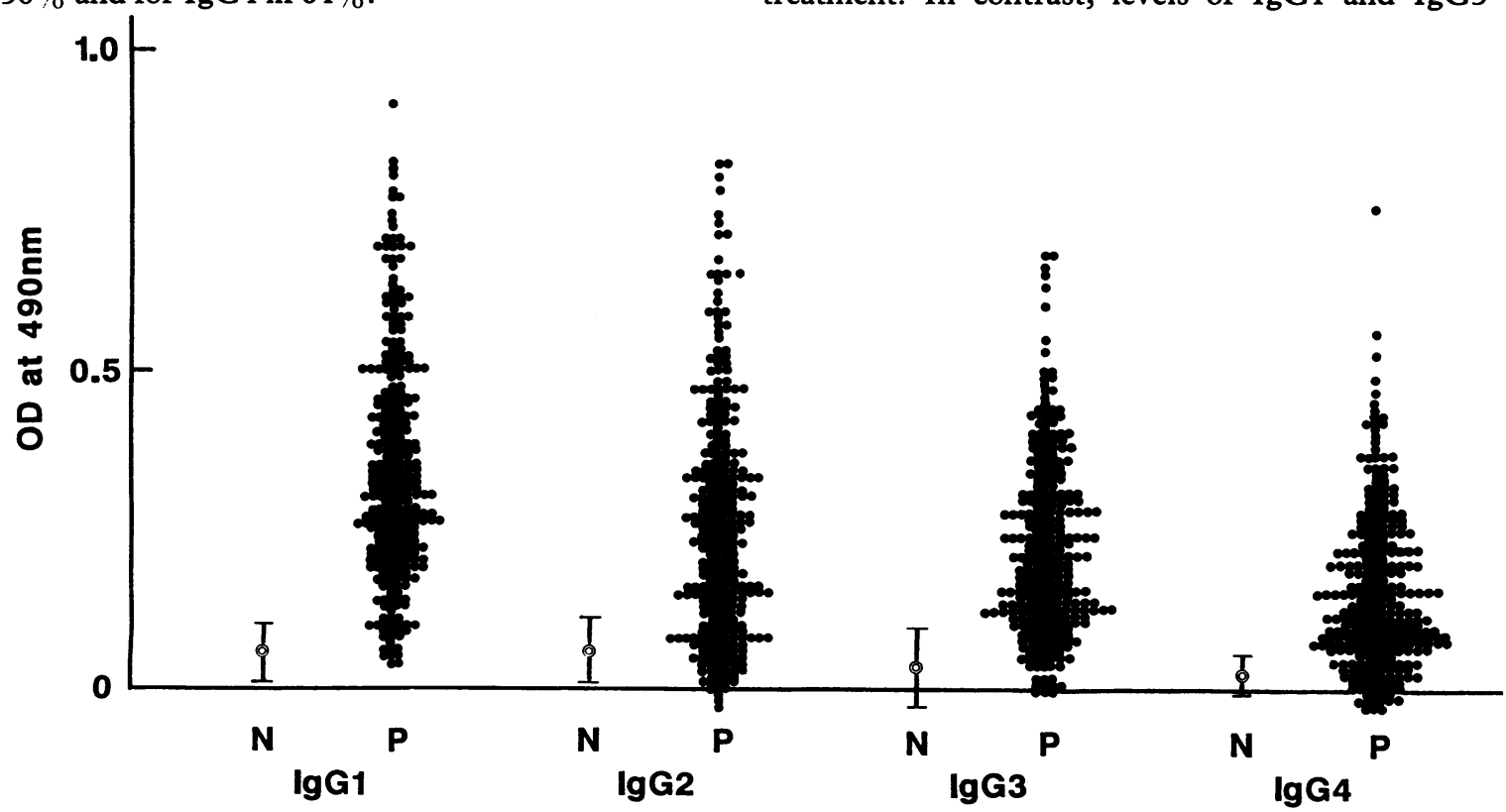

IgG subclass-specific anti-TP antlbodies
2. Levels of antibodies of the Ig classes and IgG subclasses after treatment of patients with syphilis at different stages.

The specimens studied included 20 samples of serum from patients with primary syphilis, 12 from those with secondary syphilis, 12 from those with early latent syphilis, and 99 from those with late latent syphilis. In the case of all these stages, except the late latent stage, the specimens included sera obtained prior to treatment (group A) and sera obtained at three months after the initiation of treatment (group B). All sera from the late latent stage were from treated patients, being classified as group B.

There was a significant decrease in the level of IgM antibodies within three months after treatment in cases of primary syphilis; the decrease was most conspicuous in this class as compared with the other classes (table 1). In cases of secondary syphilis and early latent syphilis, no such significant decrease in levels of IgM antibodies was observed. The level of IgM antibodies was high during the primary and secondary stages but fell by about $50 \%$ in cases of early latent syphilis. Changes in levels of IgA antibodies showed essentially the same trends as those in IgM antibodies.

Levels of antibodies in all subclasses of IgG were lowest in cases of primary syphilis and showed a significant decrease 3 months after the initiation of treatment. In contrast, levels of IgG1 and IgG3

Figure 2 Levels of anti-T p-allumum IgG subclasses in syphilis patients. $N$ denotes normal sera, and $P$ denotes sera of serologically documented syphilitic patients. OD value in normal sera at $490 \mathrm{~nm}$ : IgG1,0.059, SD 0.046; IgG2, 0.063, $S D 0.052 ; \operatorname{IgG3}, 0.040, S D 0.065$; and IgG4, 0.033, SD 0.028. 
Table 1 Levels of anti-T pallidum IgM, IgA and IgG subclass antibody in various stages of syphilis

\begin{tabular}{|c|c|c|c|c|c|}
\hline \multirow[b]{2}{*}{ Antibody } & & \multicolumn{4}{|l|}{ Stage } \\
\hline & & Primary & Secondary & Early latent & Late latent \\
\hline IgG1 & $\begin{array}{l}\mathbf{A}^{\star} \\
\mathbf{B}^{\star}\end{array}$ & $\begin{array}{l}0.421,0.236 \dagger \\
0.289,0.166 \\
(p<0.01) \ddagger\end{array}$ & $\begin{array}{l}0.568,0.172 \\
0.465,0.134 \\
(p<0.001)\end{array}$ & $\begin{array}{l}0 \cdot 483,0 \cdot 177 \\
0 \cdot 380,0 \cdot 215\end{array}$ & $\overline{0.326,0.151}$ \\
\hline IgG2 & $\begin{array}{l}\mathbf{A} \\
\mathbf{B}\end{array}$ & $\begin{array}{l}0.301,0.183 \\
0.194,0.097 \\
(p<0.01)\end{array}$ & $\begin{array}{l}0.399,0.154 \\
0.378,0.151\end{array}$ & $\begin{array}{l}0.384,0.242 \\
0.305,0.285\end{array}$ & $\overline{0 \cdot 218}, 0 \cdot 185$ \\
\hline IgG3 & $\begin{array}{l}\mathbf{A} \\
\mathbf{B}\end{array}$ & $\begin{array}{l}0.253,0.144 \\
0.110,0.074 \\
(p<0.001)\end{array}$ & $\begin{array}{l}0.352,0.098 \\
0.289,0.110 \\
(p<0.02)\end{array}$ & $\begin{array}{l}0.352,0.159 \\
0.261,0.147 \\
(p<0.02)\end{array}$ & $\overline{0.208}, 0.125$ \\
\hline IgG4 & $\begin{array}{l}\mathbf{A} \\
\mathbf{B}\end{array}$ & $\begin{array}{l}0.203,0.146 \\
0.089,0.071 \\
(p<0.01)\end{array}$ & $\begin{array}{l}0.290,0.098 \\
0.250,0.109\end{array}$ & $\begin{array}{l}0.242,0.167 \\
0.161,0.109 \\
(p<0.02)\end{array}$ & $\overline{0.137}, 0.100$ \\
\hline IgM & $\begin{array}{l}\mathbf{A} \\
\mathbf{B}\end{array}$ & $\begin{array}{l}0.406,0.356 \\
0.119,0.098 \\
(p<0.01)\end{array}$ & $\begin{array}{l}0.429,0.364 \\
0.282,0.168\end{array}$ & $\begin{array}{l}0.214,0.153 \\
0.143,0.054\end{array}$ & $\overline{0.133}, 0.125$ \\
\hline IgA & $\begin{array}{l}\mathbf{A} \\
\mathbf{B}\end{array}$ & $\begin{array}{l}0.32,0.211 \\
0.196,0.108 \\
(p<0.02)\end{array}$ & $\begin{array}{l}0.374,0.107 \\
0.268,0.077\end{array}$ & $\begin{array}{l}0.264,0.212 \\
0.179,0.097\end{array}$ & $\overline{0.199,0 \cdot 101}$ \\
\hline
\end{tabular}

$\star A$, values at the start of treatment; $B$, value at 3 months of treatment. tFigures represent the OD at $490 \mathrm{~nm}$ expressed as mean, 2SD.

$\ddagger$ Paired sample $t$ test.

antibodies fell significantly 3 months after treatment in cases of secondary syphilis, and those of IgG3 and IgG4 antibodies also fell significantly in cases of early latent syphilis.

3. Changes in levels of $\operatorname{Ig} M, I g A$ and of antibodies in IgG subclasses after treatment.

Individual patients with syphilis at various stages were followed from the start of their treatment to measure changes in levels of antibody classes (table 2). In a detailed examination of 13 cases of primary syphilis, levels of $\operatorname{IgM}$ antibodies tended to decrease in 10 cases $(77 \%)$, those of IgA antibodies in nine cases $(69 \%)$ and those of one or more of the IgG subclasses in 10 cases $(77 \%$ ) within three months after the start of treatment. In seven (54\%) of these cases, a decrease in levels of $\operatorname{IgM}, \operatorname{IgA}$ and in one or more subclasses of IgG was evident. Particularly noteworthy was the finding that there were three patients $(23 \%)$ with levels of IgM antibodies that were within normal limits before treatment. One of these patients exhibited a decrease in level of IgA antibodies and another patient showed a decrease in levels of antibodies belonging to subclasses IgG1 and 4 within three months after the start of treatment (data not shown). The remaining case had normal levels of $\operatorname{IgM}$ and $\operatorname{IgA}$ antibodies before treatment and showed no appreciable decrease in levels of $\mathrm{IgG}$ subclasses after treatment.

Of eight cases of secondary syphilis, a decrease in levels of $\mathrm{IgM}$ antibodies after treatment was noted in $\operatorname{six}(75 \%), \mathrm{IgA}$ antibodies in three cases $(38 \%)$ and in one or more subclasses of IgG in three (38\%). There were two cases $(25 \%)$ with either consistently normal levels of $\mathrm{IgM}$ antibodies or with no detectable decrease in levels of the antibodies in this class, in which, nevertheless, levels of antibodies of the IgA and IgG subclass fell after treatment. A decrease in levels of IgM antibodies after treatment occurred in two $(33 \%)$ of six patients with early latent syphilis while the remaining four patients $(67 \%)$ showed no change or normal levels in this respect. However, levels of one or more subclasses of IgG showed a decrease in two of these four cases (33\%) after treatment. In one of four cases $(25 \%)$ of late latent syphilis, levels of $\operatorname{IgM}$ and IgA classes and of all IgG subclasses decreased after treatment. Levels of IgM

Table 2 Trend of anti-T pallidum Ig isotype responses in patients after treatment

\begin{tabular}{|c|c|c|c|c|c|c|c|}
\hline \multicolumn{3}{|c|}{ Antibody } & \multicolumn{5}{|l|}{ Stage } \\
\hline$I g M$ & $\operatorname{Ig} A$ & $\operatorname{Ig} G$ & Primary & Secondary & $\begin{array}{l}\text { Early } \\
\text { latent }\end{array}$ & $\begin{array}{l}\text { Late } \\
\text { latent }\end{array}$ & Total \\
\hline 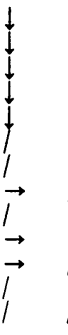 & $\begin{array}{l}\downarrow \\
1 \\
1 \\
1 \\
1 \\
\overrightarrow{1} \\
1 \\
\overrightarrow{1} \\
\overrightarrow{1}\end{array}$ & $\begin{array}{l}\downarrow \\
\vec{\downarrow} \\
\downarrow \\
\vec{\downarrow} \\
\downarrow \\
\downarrow \\
\rightarrow \\
\rightarrow \\
\vec{\rightarrow} \\
\rightarrow\end{array}$ & $\begin{array}{l}7 \\
1 \\
0 \\
2 \\
0 \\
0 \\
1 \\
0 \\
1 \\
0 \\
0 \\
0 \\
1\end{array}$ & $\begin{array}{l}1 \\
2 \\
2 \\
0 \\
1 \\
0 \\
0 \\
0 \\
0 \\
1 \\
0 \\
1 \\
0\end{array}$ & $\begin{array}{l}1 \\
1 \\
0 \\
0 \\
0 \\
1 \\
0 \\
1 \\
0 \\
0 \\
1 \\
0 \\
1\end{array}$ & $\begin{array}{l}1 \\
0 \\
0 \\
0 \\
0 \\
0 \\
0 \\
1 \\
0 \\
0 \\
1 \\
0 \\
1\end{array}$ & $\begin{array}{r}10 \\
4 \\
2 \\
2 \\
1 \\
1 \\
1 \\
2 \\
1 \\
1 \\
2 \\
1 \\
3\end{array}$ \\
\hline \multicolumn{3}{|c|}{ Total } & 13 & 8 & 6 & 4 & 31 \\
\hline
\end{tabular}

*ELISA index at 3 months after treatment: $\downarrow$, decrease by half or more below the initial (pre-treatment) level; $\rightarrow$, changed otherwise; /, remained within normal limits. For IgG, the same apply to observed changes in one or more of the IgG subclass (1 to 4). 


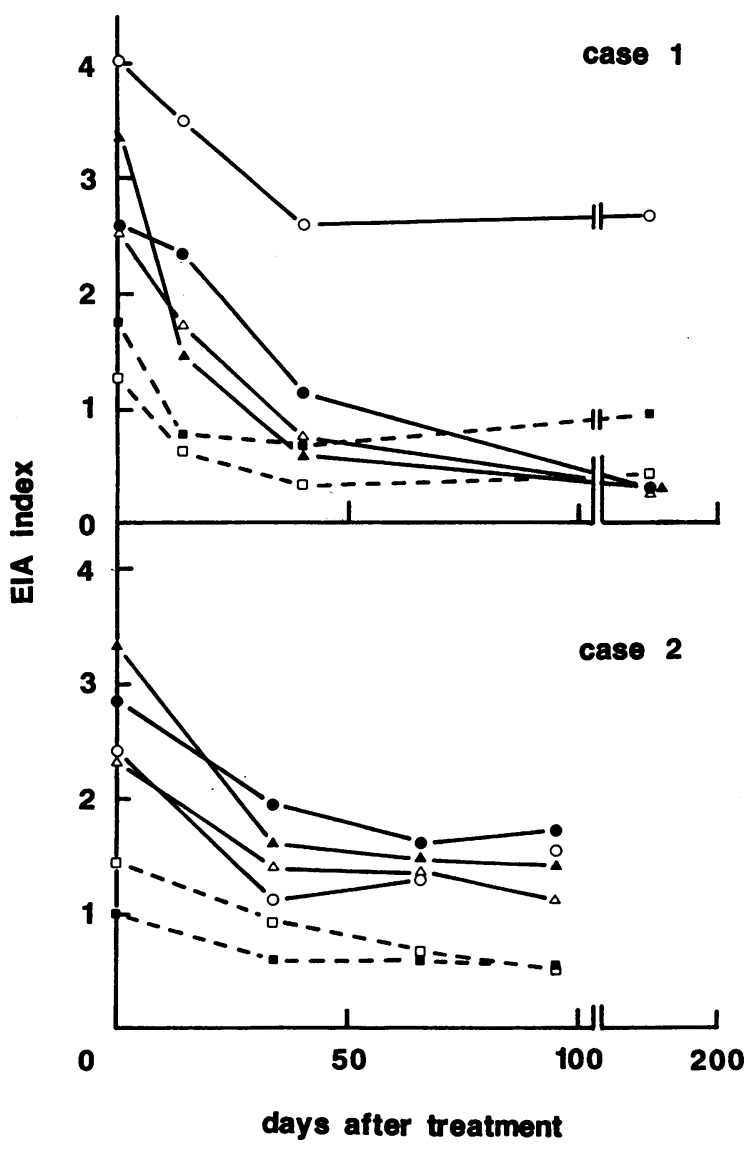

Figure 3 Changes of anti-T pallidum antibody isotype levels after treatment in patient with primary syphilis. Symbols: O IgG1; IgG2; IgG3; $\triangle$ IgG4; $\square$ IgM; IgA. An ELISA index of 1 denotes the upper normal limit $(\bar{x}+2 S D)$.

antibodies remained unaltered or within the normal limits despite treatment in the other three patients, of whom one $(25 \%)$ displayed a decline in levels of antibodies in subclasses IgG2 and IgG4 of IgG.

The serial changes seen in some of the cases outlined in table 2 are illustrated in figs 3 to 5 . Figure 3 depicts changes in levels of antibodies observed after treatment in patients with primary syphilis. As can be seen, levels of antibodies in classes of $\mathrm{Ig}$ and in all subclasses of IgG, except IgG1, fell below the upper limit of normal on day 40 after the start of treatment in Case 1 (upper panel). In Case 2, levels of IgA antibodies were within normal limits even before treatment and remained there. Levels of antibodies in all subclasses of IgG displayed a marked decrease within $\mathbf{3 0}$ days after treatment and remained at the lowered values, or near them, thereafter. Levels of IgA antibodies fell gradually after treatment and reached a normal level on day 30 (lower panel).
The upper panel of fig 4 illustrates a rare example associated with a case of secondary syphilis. The patient received penicillin at $750 \mathrm{mg} /$ day over a period of eight weeks. The treatment produced a remarkable amelioration of symptoms, yet levels of IgM, IgG2 and IgG3 antibodies rose briefly and then declined while those of IgA, IgG1 and IgG4 gradually decreased after treatment. This case is classified as unaltered with respect of levels of all antibody isotypes in table 2. In Case 2 (lower panel), a marked decrease in level of IgM antibodies and a moderate decrease in level of IgG1 antibody occurred whereas levels of the remaining isotypes showed no noticeable changes.

In Case 1 of early latent syphilis (upper panel, fig 5), levels of IgG1, IgG2 and IgG3 antibodies decreased moderately after treatment. The patient in Case 2, whose levels of IgM and IgA antibodies were consistently within the normal limits, even prior to treatment, showed a decrease in levels of antibodies in IgG subclasses IgG2 and IgG4 after treatment (lower panel).

The patient with late latent syphilis, whose course is shown in fig 6 , responded to treatment with a

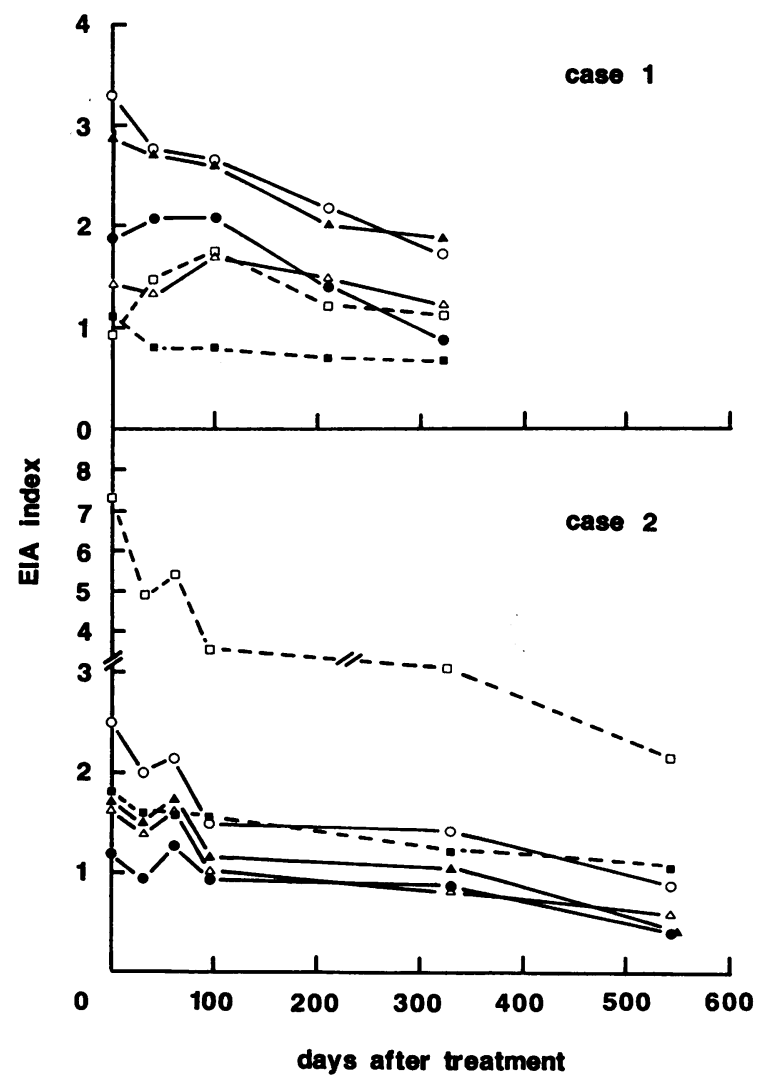

Figure 4 Changes of anti-T pallidum antibody isotype levels after treatment in patient with secondary syphilis. The same symbols as in fig 3 apply to this chart. 


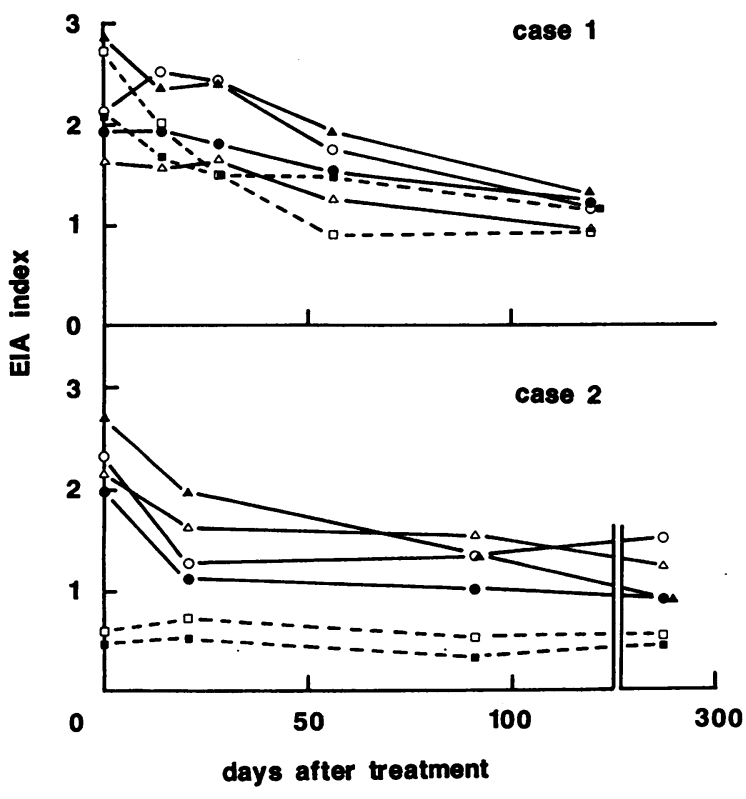

Figure 5 Changes in anti-T pallidum antibody isotype levels after treatment in patients with early latent syphilis. The same symbols as in fig 3 apply to this chart.

marked decrease in levels of IgM, IgA and IgG3 antibodies while levels of IgG2, IgG3 and IgG4 antibodies declined gradually over an extended period of time.

\section{Discussion}

It is generally recognised at present that IgM antibodies against $T$ pallidum antigen, among the various classes of $\mathrm{Ig}$, are useful as a serodiagnostic marker for the evaluation of the results of treatment. The present data demonstrate that levels of IgM antibodies reflect the effects of treatment, and that these changes are the most conspicuous when compared with changes in levels of the other classes of antibodies. Nevertheless, levels of IgM antibodies may remain within normal limits despite infection or may fail to decrease, in spite of treatment, in occasional cases. In the present series of 31 patients seven patients $(23 \%)$ were in the former category and five patients $(16 \%)$ in the latter, when the serodiagnostic procedure described herein was used. IgM antibodies are of little use as a marker for evaluating the effects of treatment in such cases. However, a decrease in levels of antibodies in IgG subclasses was evident in four $(33 \%)$ ) of these 12 cases and a decrease in level of IgA antibodies in another case. Measurements of levels of antibodies of the IgG subclasses and of IgA may therefore provide confirmatory evidence for syphilis, in those cases where levels of IgM antibodies fail to serve as a useful parameter for the evaluation of the results of treatment. It is, however, unwise to confine the choice of a marker to any particular IgG subclass(es), and it is clearly necessary to measure the levels of antibodies in all IgG subclasses inasmuch as the responding subclasses of IgG antibodies vary from patient to patient.

Puritz et al found that only IgG1 was detected in patients with primary and secondary syphilis and that IgG1 was dominant, with low levels of IgG3 and IgG4, in tertiary syphilis. ${ }^{10}$ In the study by van der Sluis et al IgG1 and IgG3 were noted to as the principal subclasses of antibodies in patients with primary syphilis. ${ }^{11}$ Baughn et al demonstrated IgM and IgG1 in patients with primary syphilis and IgM, IgG1 and IgG3 in those with secondary syphilis. ${ }^{12}$ The reports of these three groups of investigators are in agreement with respect to the observation that levels of IgG2 and IgG4 antibodies in patients ${ }^{2}$ sera were extremely low. In the present series, anti-T pallidum antibodies of the various classes of $\mathrm{Ig}$ and subclasses of IgG were demonstrated at all stages of the disease, regardless of whether it was treated or untreated. Of the sero-positive sera studied, levels above the upper limit of normal were detected for IgG1 antibody in $77 \%$, for IgG2 antibody in $64 \%$, for IgG3 antibody in $56 \%$, and for IgG4 antibody is $64 \%$ of samples. The relative levels of antibodies in the IgG subclasses in patients' sera were noted to be in order: IgG1 > IgG3 $\fallingdotseq$ IgG2 > IgG4, although a precise comparison is impracticable because of possible differences in the affinity of the secondantibody preparation used in this study. It is unlikely that the disparity between the present data and those of three other groups mentioned is due to the

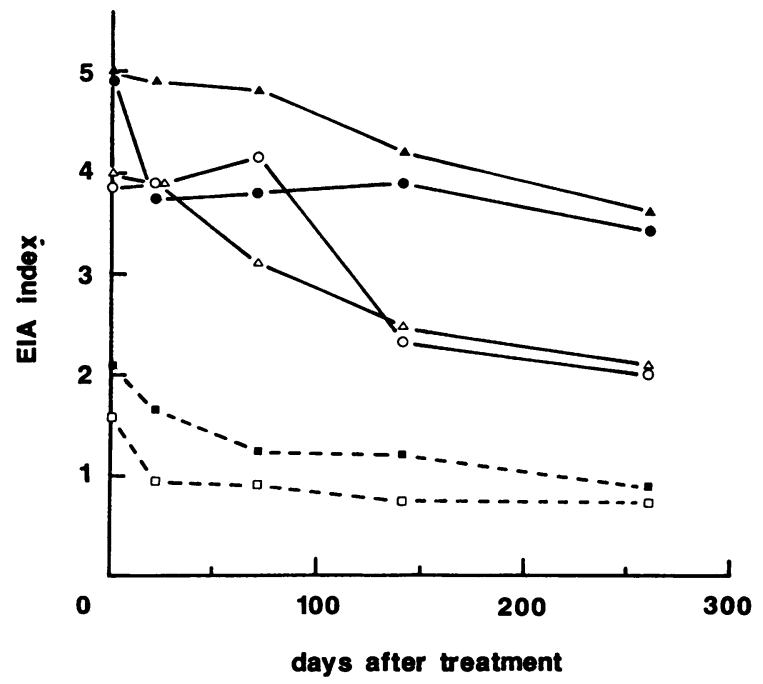

Figure 6 Changes of anti-T pallidum antibody isotype levels after treatment in patient with late latent syphilis. The symbols as in fig 3 apply to this chart. 
specificity of polyclonal antibodies used as second antibodies in our experiments, because we confirmed the specificity of the antibodies by using myeloma proteins that belonged to the respective subclasses in preliminary experiments (data not shown). It is, therefore, difficult to explain the reasons for the disparity at this time.

Correspondence to Dr Shinobu Tanaka, Department of Laboratory Animal Science, Tokyo Metropolitan Institute of Medical Science, 3-18-22, Honkomagome, Bunkyo-ku, Tokyo 113, Japan.

1 Johnston NA. Neonatal congenital syphilis. Diagnosis by the absorbed fluorescent treponemal antibody (IgM) test. $\mathrm{Br} J$ Venereal Dis 1972;48:464-9.

2 O'Neil P, Nicol CS. IgM class antitreponemal antibody in treated and untreated syphilis. Br J Venereal Dis 1972;48: $460-3$.

3 Hunter EF. The fluorescent treponemal antibody-absorption (FTA-ABS) test for syphilis. CRC Crit Rev Clin Lab Sci 1975;5:315-30.

4 Wilkinson AF, Rodin P. FTA-IgM test in syphilis in adults. Its relation to clinical findings. BrJ Venereal Dis 1976;52:219-23.

5 Shannon R, Booth SD. The pattern of immunological responses at various stages of syphilis. $B r J$ Venereal Dis 1977;53:281-6.

6 Tanaka S, Suzuki T, Numata T. Treponema pallidum immune adherence test for serodiagnosis of syphilis. 3. Clinical significance and evaluation of treatment. $B r J$ Venereal Dis 1978;54:380-5.

7 Nelson Jr, RA. The immune-adherence phenomenon. An immunologically specific reaction between microorganisms and erythrocytes leading to enhanced phagocytosis. Science 1953;118:733-7.

8 Bindon CJ, Hale G, Bruggemann W, Waldmann H. Human monoclonal IgG isotypes differ in complement activating function at the level of $\mathrm{C} 4$ as well as Clq. $J$ Exp Med 1988;168:127-40.

9 Puritz EM, Thompson Jr, JA, Dierberg F, Kraus SJ, Young WJ. IgG subclasses of fluorescent treponemal antibodies: Correlation with complement fixation and clinical stage. Clin Immunol Immunopath 1975;4:352-61.

10 van der Sluis JJ, van Reede EC, Boer M. Immunoglobulin G subclasses of fluorescent anti-Treponema pallidum antibodies: Evidence for sequential development of specific anti- $T$ pallidum immunoglobulin $G$ response in patients with early syphilis. J Clin Microbiol 1986;24:418-23.

11 Baughn RE, Jorizzo JL, Adaus CB, Musher DM. Ig class and IgG subclass responses to Treponema pallidum in patients with syphilis. J Clin Immunol 1988;8:128-39.

12 Baughn RE, McNeely MC, Jorizzo JL, Musher DM. Characterisation of the antigenic determinants and host components in immune complexes from patients with secondary syphilis. $J$ Immunol 1986;136:1406-14.

Accepted 22 January 1990 